\title{
Efficacy of serum chitotriosidase activity in early treatment of patients with active tuberculosis and a negative sputum smear
}

This article was published in the following Dove Press journal:

Therapeutics and Clinical Risk Management

24 August 2012

Number of times this article has been viewed

\section{Canturk Tasci' \\ Serkan Tapan ${ }^{2}$ \\ Sevket Ozkaya ${ }^{3}$ \\ Ersin Demirer ${ }^{4}$ \\ Omer Deniz' \\ Arzu Balkan' \\ Metin Ozkan' \\ Ilker Inan' \\ Ismail Kurt ${ }^{2}$ \\ Hayati Bilgic'}

'Department of Pulmonary Diseases, ${ }^{2}$ Department of Biochemistry, Gulhane Medical Faculty, Ankara, ${ }^{3}$ Department of Pulmonary Medicine, Dr Suat Seren Education and Research Hospital for Chest Diseases and Thoracic Surgery, Izmir, ${ }^{4}$ Istanbul Gulhane Medical Faculty, Department of Pulmonary Diseases, Istanbul, Turkey
Correspondence: Canturk Tasci Gülhane Askeri Tıp Akademisi, Göğüs Hastalıkları AD, AAnkara, Türkiye Tel +903123044406

Email ctasci@gata.edu.tr
Background: The results of sputum culture for Mycobacterium tuberculosis must be awaited in most cases, which delays the start of treatment in patients with sputum smear-negative pulmonary tuberculosis. We investigated whether plasma chitotriosidase activity is a strong marker for early diagnosis of tuberculosis in patients for whom a bacillus smear is negative and tuberculosis culture is positive.

Methods: Clinical, radiological, and laboratory features were evaluated in 75 patients, 17 of whom were diagnosed as having active tuberculosis by negative acid-fast bacillus smear and positive culture, 38 as having sequel tuberculosis which was radiologically and microbiologically negative, and 20 who served as healthy controls. Serum chitotriosidase activity levels were measured in both cases and controls.

Results: The mean age of the cases with active pulmonary tuberculosis, cases with sequel lesions, and controls was $23 \pm 2.4$ years, $22 \pm 1.7$ years, and $24 \pm 2.1$ years, respectively. Serum chitotriosidase levels were $68.05 \pm 72.61 \mathrm{nmol} /$ hour $/ \mathrm{mL}$ in smear-negative, culture-positive pulmonary tuberculosis cases (Group A) and $29.73 \pm 20.55 \mathrm{nmol} /$ hour $/ \mathrm{mL}$ in smear-negative, culture-negative sequel pulmonary tuberculosis cases (Group B). Serum chitotriosidase levels from patients in Group A were significantly higher than in Group B and Group C. There was no statistically significant difference in serum chitotriosidase levels between cases with sequel pulmonary tuberculosis (Group B, smear-negative, culture-negative) and healthy controls (Group C).

Conclusion: In patients with active tuberculosis and a negative sputum smear for acid-fast bacillus, plasma chitotriosidase activity seems to be a strong marker for diagnosis of active disease which can be used while awaiting culture results.

Keywords: pulmonary tuberculosis, serum chitotriosidase, diagnosis, antituberculous treatment, disease activity

\section{Introduction}

Tuberculosis is a disease for which treatment becomes more challenging day by day due to its contagious nature and the increasing number of resistant cases. Moreover, the mortality and morbidity associated with the disease is high, so early diagnosis of cases is necessary. Today, the most common method used for early detection of pulmonary tuberculosis is determination of acid-fast bacillus in a sputum smear, and the most accurate diagnostic method is culture of Mycobacterium tuberculosis in lung tissue samples obtained from suspected cases. According to data from the Centers for Disease Control, only $80.2 \%$ of sputum cultures are positive for breeding $M$. tuberculosis bacillus, and the remainder of cases are negative both for smear and culture. ${ }^{1}$ Moreover, breeding of bacillus in culture takes 3-4 weeks, so the diagnosis cannot be made in a 
timely fashion, and potentially unnecessary treatment with possible side effects must be started prophylactically before the final diagnosis. For this reason, new cell culture methods are under investigation, along with different molecules, and biologic and serologic tests..$^{2-4}$

Chitotriosidase is an enzyme secreted mainly by macrophages, belongs to the chitinase protein family, and has a mass of about $50 \mathrm{kDa}$. In many diseases, including lysosomal storage diseases such as Gaucher's disease, beta thalassemia, acute malaria (induced by Plasmodium falciparum), systemic candidiasis, and granulomatous diseases, serum chitotriosidase may be increased. It is known that chitotriosidase can be used as a marker for macrophage activation. ${ }^{5}$ Plasma chitotriosidase activity has been studied in many lung diseases, especially interstitial lung diseases and sarcoidosis, but its role in the early diagnosis of active tuberculosis has been studied only in a limited number of patients. When the tuberculosis bacillus reaches the alveoli in the upper airways, it is engulfed by alveolar macrophages. Some bacilli are destroyed by these macrophages, but some multiply within the macrophage and eat their way outwards after piercing the macrophage. During this time, the macrophages present bacillary antigens to $\mathrm{T}$ helper lymphocytes and stimulate them by secreting interleukin-1. The activated lymphocytes also secrete various lymphokines. All these events come together to trigger the immune response. ${ }^{6}$ In this study, we investigated whether plasma chitotriosidase activity is a useful marker for early diagnosis of tuberculosis in patients who are bacillus smear-negative and culture-positive.

\section{Materials and methods}

Seventeen patients diagnosed as having active tuberculosis by negative acid-fast bacillus smear and positive culture, 38 patients with inactive tuberculosis who were radiologically and microbiologically negative, and 20 healthy controls were recruited from our hospital for this study. Posteroanterior chest radiography, complete blood count, erythrocyte sedimentation rate, and routine biochemical tests were performed in all cases with active or sequel pulmonary tuberculosis. High-resolution computed tomography of the lungs were performed for patients in whom the distinction between active and sequel tuberculosis could not be made on the basis of clinical and laboratory investigations. The local ethics committee approved the study. A signed patient consent form was obtained from all participants.

Microbiologic assessment was done by sputum smear in triplicate. For patients who did not produce a sputum sample, microbiologic assessment was done by positive acid-fast bacillus in bronchoalveolar lavage material via bronchoscopy and by gastric lavage material. Patients with a negative acid-fast bacillus smear were recruited and divided into three groups: Group A, comprising patients with active tuberculosis who had negative plasma chitotriosidase activity and a negative acid-fast bacillus smear, but had a positive culture; Group B, consisting of patients with radiological sequel tuberculosis and a negative acid-fast bacillus smear, but had a negative culture; and Group C, consisting of healthy controls.

Blood samples were drawn from all groups to investigate the activity of serum chitotriosidase. Serum samples were kept at -80 degrees centigrade and studied immediately. Enzyme activity in serum was evaluated using a fluorometric method reported by Guo et $\mathrm{al}^{7}$ and modified for our study. The study data were analyzed using the Statistical Package for Social Sciences for Windows version 16.0 (SPSS Inc, Chicago, IL). Comparisons were made using the Pearson-Chi square test, and $P$ values $<0.05$ were considered to be statistically significant.

\section{Results}

Patient demographic characteristics and study results are shown in Table 1. All cases and controls were male, because the study was designed and performed in a military hospital. The mean age of cases with active pulmonary tuberculosis, those with inactive disease, and control subjects was $23 \pm 2.4$ years, $22 \pm 1.7$ years, and $24 \pm 2.1$ years, respectively. Serum chitotriosidase levels were $68.05 \pm 72.61 \mathrm{nmol} / \mathrm{hour} / \mathrm{mL}$ in smear-negative, culture-positive pulmonary tuberculosis cases (Group A) and $29.73 \pm 20.55 \mathrm{nmol} /$ hour $/ \mathrm{mL}$ in smearnegative, culture-negative inactive pulmonary tuberculosis cases (Group B). The serum chitotriosidase level in Group A patients was higher than that in Group B and Group C patients and the difference was statistically significant $(P<0.05)$. Figure 1 shows the distribution of serum chitotriosidase levels in the active and inactive cases of pulmonary tuberculosis. There was no statistically significant difference between serum chitotriosidase levels in cases with sequel pulmonary

Table I Characteristics of patients

\begin{tabular}{llll}
\hline Characteristics & Group A & Group B & Group C \\
\hline Patients (n) & 17 & 38 & 20 \\
Age (mean \pm SD), years & $23 \pm 2.4$ & $22 \pm 1.7$ & $24 \pm 2.1$ \\
Male/female & $17 / 0$ & $38 / 0$ & $20 / 0$ \\
Chitotriosidase level, nmol/ & $68.0 \pm 72.6^{\dagger}$ & $29.7 \pm 20.5$ & $28.4 \pm 13.8$ \\
hour/mL (mean \pm SD) & & & \\
\hline
\end{tabular}

Notes: Group A, patients with smear-negative, culture-positive pulmonary tuberculosis. Group B, patients with smear-negative, culture-negative inactive of pulmonary tuberculosis. Group $C$, healthy controls. ${ }^{\dagger} P<0.05$. 


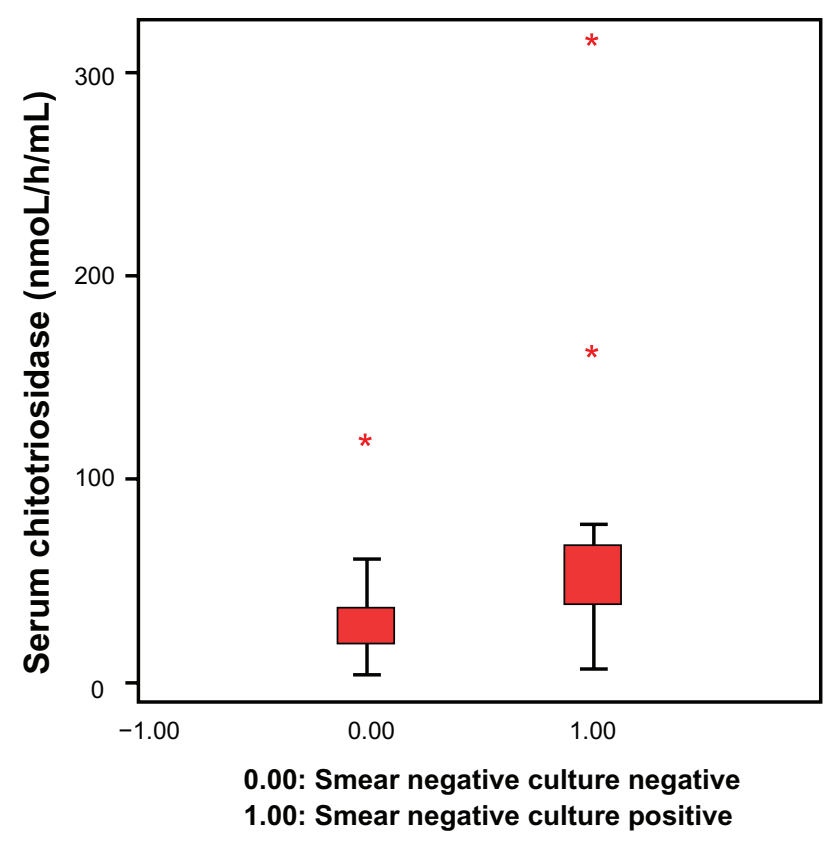

Figure I Distribution of serum chitotriosidase levels in patients with active and inactive pulmonary tuberculosis.

tuberculosis (Group B, smear-negative, culture-negative) and healthy controls (Group C, $P>0.05$ ).

\section{Discussion}

In this study, we demonstrated that serum chitotriosidase levels in patients with pulmonary tuberculosis were significantly higher than in healthy controls. No statistically significant difference was found between serum chitotriosidase levels from smear-negative and culture-negative cases (accepted as sequel pulmonary tuberculosis for the purposes of this study) and those from healthy controls. It is known that serum chitotriosidase levels are generally under $18 \mathrm{nM} /$ hour $/ \mathrm{mL}$ in healthy people. ${ }^{8}$ Duplication during chitotriosidase gene activation is seen in approximately $5 \%$ of the general population, which makes it impossible to measure serum levels of the enzyme in patients with tuberculosis. ${ }^{9,10}$

As is well known, pulmonary tuberculosis is a result of a granulomatous reaction activated by $M$. tuberculosis, and macrophages play an important role in granuloma formation. Macrophage activation increases production of interferondelta and tumor necrosis factor-alpha, which indirectly leads to increased serum levels of chitotriosidase. High serum chitotriosidase has been demonstrated previously in granulomatous diseases, including sarcoidosis and tuberculosis. High serum chitotriosidase is also a typical marker of Gaucher's disease and is directly related to the immune response. ${ }^{11}$

Despite the fact that this study population was small, ours is the first study to the authors' knowledge which investigates whether plasma chitotriosidase activity is a useful tool for early diagnosis of tuberculosis. Although there is a paucity of published studies for comparison, Bargagli et al have studied plasma chitotriosidase activity in patients with sarcoidosis and tuberculosis. ${ }^{12}$ In their study, they had 96 sarcoidosis patients, 15 tuberculosis patients, and 30 healthy controls, and reported that plasma chitotriosidase activity was significantly higher in patients with sarcoidosis than in patients with tuberculosis and healthy controls. Plasma chitotriosidase activity was twice as high in patients with tuberculosis than in healthy controls; however, the difference was not statistically significant. Of the 15 patients with tuberculosis recruited into that study, seven were female, and their mean age was 58.3 years. In our present study, the mean age of Group A patients was 23 years. In the study by Bargagli et al, 14 of 15 patients were diagnosed to have lung tuberculosis by a positive acid-fast bacillus sputum smear and positive culture, and only one patient was diagnosed by a negative acid-fast bacillus sputum smear and bacillus-positive polymerase chain reaction procedure in lung tissue, which is similar to our study. One of the 15 patients had plasma chitotriosidase activity over $60 \mathrm{nmol} / \mathrm{mL} /$ hour and it is not clear if this was the patient for whom acid-fast bacillus was negative. Therefore, it should be concluded that plasma chitotriosidase activity increases later on in the disease when an acid-fast bacilli sputum smear is negative.

Our study has some limitations, the most important of which is its small patient population. Even though it is the first study investigating plasma chitotriosidase activity in patients with active and sequel tuberculosis in comparison with healthy controls, and plasma chitotriosidase activity, despite the limited number of patients is a powerful marker of active tuberculosis. However, we hope that the results of our study will encourage further investigation on this subject. In conclusion, in patients with active tuberculosis and a negative sputum smear for acidfast bacillus, plasma chitotriosidase activity can be a strong marker for diagnosis of active disease pending availability of culture results.

\section{Disclosure}

The authors report no conflicts of interest in this work.

\section{References}

1. American Thoracic Society and Centers for Diseases Control and Prevention. Treatment of tuberculosis infection in adults and children. Am Rev Respir Dis. 1994;263:1359-1374.

2. Chan ED, Heifets L, Iseman MD. Immunologic diagnosis of tuberculosis: a review. Tuber Lung Dis. 2000;80:131-140.

3. Al Zahrani K, Jahdali H, Poirier P, et al. Accuracy and utility of commercially available amplification and serologic tests for the diagnosis of minimal pulmonary tuberculosis. Am J Respir Crit Care Med. 2000;162:1323-1329. 
4. Khomenko A, Bayensky A, Chernousova L, et al. Serodiagnosis of tuberculosis: detection of mycobacterial antibodies and antigens. Tuber Lung Dis. 1996;77:510-515.

5. Renkema GH, Boot RG, Strijland A, et al. Synthesis, sorting, and processing into distinct isoforms of human macrophage chitotriosidase. Eur J Biochem. 1997;244:279-285.

6. Kanaya AM, Glidden DV, Chambers HF. Identifying pulmonary tuberculosis in patients with negative sputum smear results. Chest. 2001;120: 349-355.

7. Guo Y, He W, Boer AM, et al. Elevated plasma chitotriosidase activity in various lysosomal storage disorders. J Inherit Metab Dis. 1995;18: 717-722.

8. Casal JA, Lacerda L, Pérez LF, et al. Relationship between serum markers of monocyte/macrophage activation in type 1 Gaucher's disease. Clin Chem Lab Med. 2002;40:52-55.
9. Hollak CE, van Weely S, van Oers MH, Aerts JM. Marked elevation of plasma chitotriosidase activity. A novel hallmark of Gaucher disease. $J$ Clin Invest. 1994;93:1288-1292.

10. Canudas J, Cenarro A, Civeira F, et al. Chitotriosidase genotype and serum activity in subjects with combined hyperlipidemia: effect of the lipid-lowering agents, atorvastatin and bezafibrate. Metabolism. 2001; 50:447-450.

11. Wajner A, Michelin K, Burin MG, et al. Biochemical characterisation of chitotriosidase enzyme. Comparison between normal individuals and patients with Gaucher and Niemann-Pick disease. Clin Biochem. 2004;37:893-897.

12. Bargagli E, Margollicci M, Nikiforakis N, et al. Chitotriosidase activity in the serum of patients with sarcoidosis and pulmonary tuberculosis. Respiration. 2007;74:548-552.

\section{Publish your work in this journal}

Therapeutics and Clinical Risk Management is an international, peerreviewed journal of clinical therapeutics and risk management, focusing on concise rapid reporting of clinical studies in all therapeutic areas, outcomes, safety, and programs for the effective, safe, and sustained use of medicines. This journal is indexed on PubMed Central, CAS,
EMBase, Scopus and the Elsevier Bibliographic databases. The manuscript management system is completely online and includes a very quick and fair peer-review system, which is all easy to use. Visit http://www.dovepress.com/testimonials.php to read real quotes from published authors.

Submit your manuscript here: http://www.dovepress.com/therapeutics-and-clinical-risk-management-journal 